\title{
Monophasic Synovialosarcoma of the Kidney: About a Case and Literature Review
}

\author{
Maryam Zaouit*, Sia Nioka Pierre Xavier, Hanan Rida, Hassan Jouhadi, Tarik Chekrine, \\ Zineb Bouchbika, Nadia Benchekroun, Nezha Tawfiq, Souha Sahraoui, Abdellatif Benider
}

Mohammed VI Center for Cancer Treatment, Ibn Rochd University Hospital, Casablanca, Morocco

Email: *meryem.zaouit@gmail.com

How to cite this paper: Zaouit, M., Xavier, S.N.P., Rida, H., Jouhadi, H., Chekrine, T., Bouchbika, Z., Benchekroun, N., Tawfiq, N., Sahraoui, S. and Benider, A. (2021) Monophasic Synovialosarcoma of the Kidney: About a Case and Literature Review. Journal of Cancer Therapy, 12, 634-640. https://doi.org/10.4236/jct.2021.1211055

Received: October 12, 2021

Accepted: November 27, 2021

Published: November 30, 2021

Copyright ( 2021 by author(s) and Scientific Research Publishing Inc. This work is licensed under the Creative Commons Attribution International License (CC BY 4.0).

http://creativecommons.org/licenses/by/4.0/

\section{(c) (i) Open Access}

\begin{abstract}
Introduction: Primary renal synovialosarcoma (SVS) is a rare and aggressive disease in which the metastatic potential is very high. Its diagnosis is based on morphological and molecular studies. No therapeutic consensus has yet been established for this histological variant of renal cancer. We describe our experience with a patient followed at the Mohamed IV Center for cancer treatment for primary monophasic synovialosarcoma of the kidney. Case Presentation: In October 2020, a 58-year-old patient with hypertension under treatment, consulted for right back pain without hematuria or calculus emission. The initial examination found a slight right lumbar tenderness. Thoraco-abdominal computed tomography revealed a cystic lesion of the superior pole of the right kidney without secondary lesions. Surgical treatment consisted of an enlarged right total nephrectomy using a bi-subcostal approach. The post-operative consequences were simple. Histologically, it was a poorly differentiated cystic malignant tumor process measuring $17 \mathrm{~cm}$ long axis. The limits were healthy as well as the adrenal. Immunohistology made it possible to retain a monophasic synovialosarcoma. However, the patient did not receive genetic analysis. Given the poor prognosis of these tumors, treatment with adjuvant chemotherapy and radiotherapy has been imposed; as indicated in our case. Conclusion: Primary kidney SVS is a rare, aggressive disease with a poor prognosis. However, the prognosis may be improved by multimodal treatment. A positive diagnosis is difficult and can be confused with other types of renal carcinoma hence the interest in molecular biology.
\end{abstract}

\section{Keywords}

Kidney, Synovialosarcoma, Molecular Study, Poor Prognosis

\section{Introduction}

Primary renal synovialosarcoma (SVS) is a rare and aggressive disease where 
metastases can occur in $50 \%$ of cases [1].

Its diagnosis is based on morphological and molecular studies demonstrating spindle cells and SYT-SSX translocation due to the difficulty in differentiating it from other renal mesenchymal tumors.

Very few publications have addressed this histological variant of primary renal cancers, taking into account; no therapeutic consensus has yet been established.

We describe our experience with an elderly patient age 54 and followed in the Mohamed IV Center for cancer treatment for primary monophasic synovialosarcoma of the kidney.

\section{Case Presentation}

In October 2020, a 58-year-old patient with hypertension under treatment, consulted for right back pain without hematuria or calculus emission. The initial clinical examination found a slight right lumbar tenderness without lumbar contact or deterioration of the general condition. The lymph node areas were free.

Thoraco-abdominal computed tomography revealed a cystic bilocular cortical lesion of the upper pole of the right kidney, measuring $160 \times 115 \times 80 \mathrm{~mm}$ in diameter, type IV according to the Bosniak classification, without secondary lesions.

Complement by abdominal MRI was done showing a large cyst involving the upper part of the right kidney with enhanced adenoids after injection of gadolinium measuring $160 \times 100 \times 113 \mathrm{~mm}$ (Figure 1 and Figure 2).

The surgical treatment consisted of a right enlarged total nephrectomy (Figure 3 ) by bi-subcostal approach. The post-operative consequences were simple.

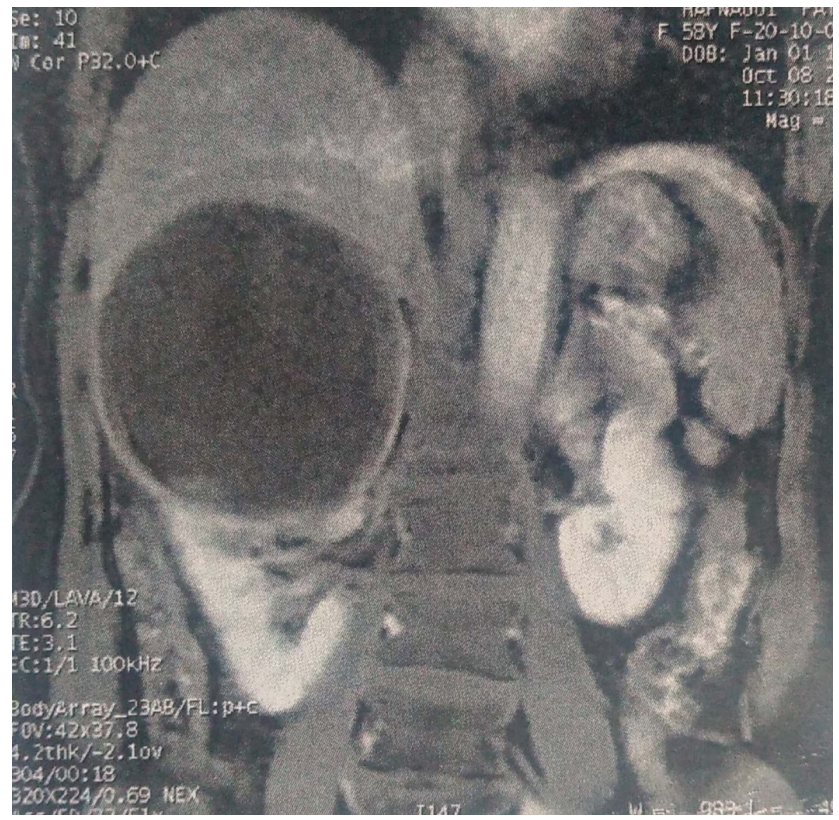

Figure 1. Abdominal MRI, Frontal section: bulky process cystic upper pole of the right kidney. 


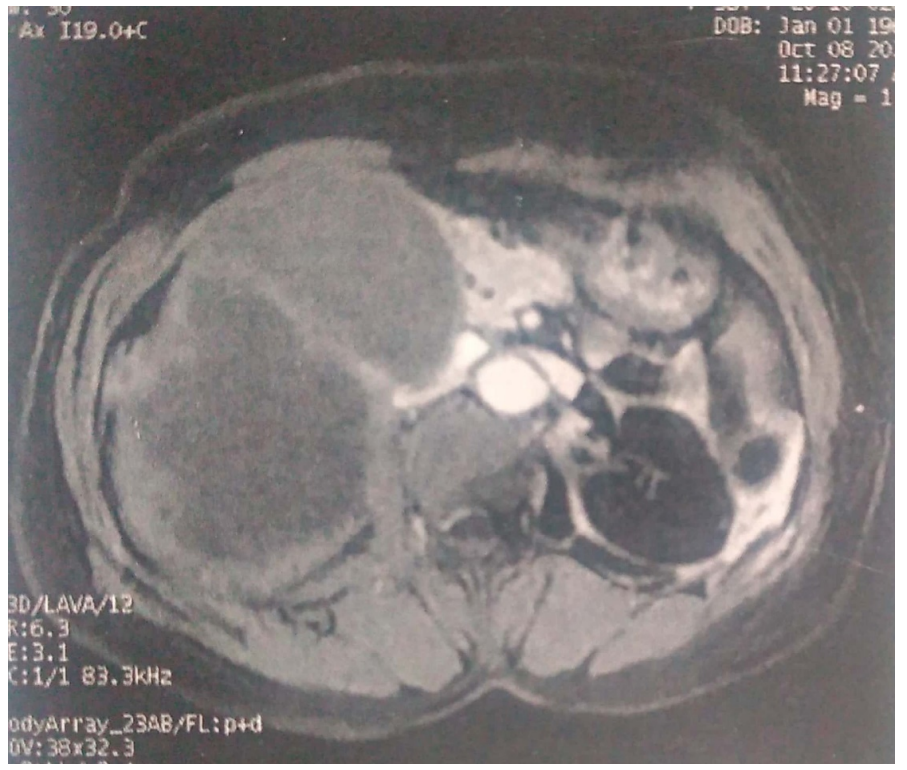

Figure 2. Abdominal MRI, Sagittal section: bilocular cystic process site of enhanced vegetation after gadolinium injection.

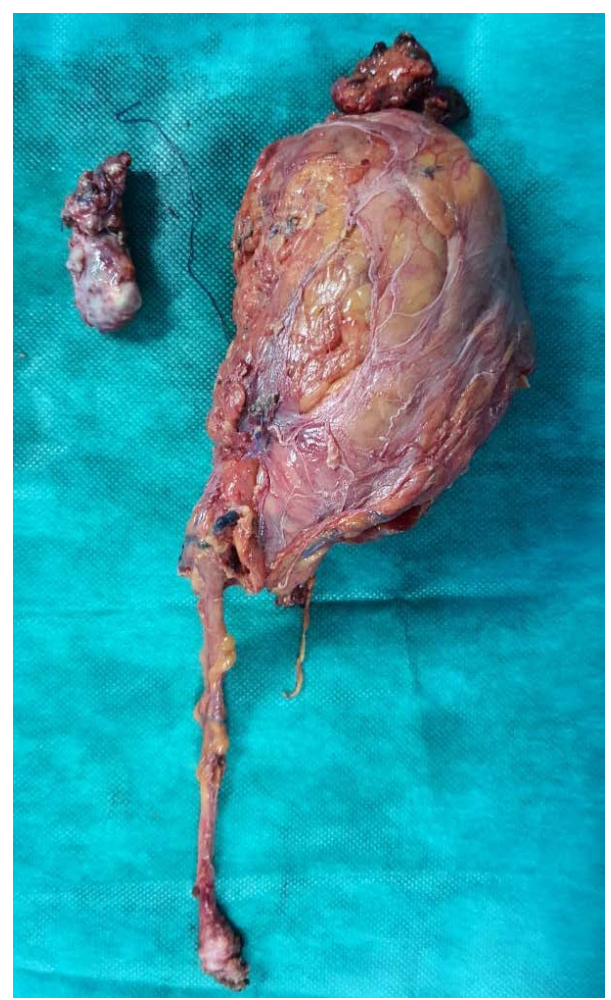

Figure 3. The right nephrouretectomy.

Histologically, it was a cystized poorly differentiated malignant tumor process measuring $170 \mathrm{~mm}$ long axis. The limits were healthy as well as the adrenal. On the immunohistological study; the fusiform component was diffusely labeled with Bcl-2a, and Ki67 was expressed at 40\%, allowing monophasic synovialosarcoma to be retained. However, the patient did not receive genetic analysis. 
Given the poor prognosis of these tumors, treatment with adjuvant chemotherapy and radiotherapy was decided in a multidisciplinary consultation meeting.

The patient received four courses of chemotherapy based on Adriamycin 60 $\mathrm{mg} / \mathrm{m}^{2}$ on D1, Ifosfamide $1800 \mathrm{mg} / \mathrm{m}^{2}$ D1-D5 and Uromitexan $1800 \mathrm{mg} / \mathrm{m}^{2}$ D1-D5. The protocol was received without incident, with very good clinical and hematological tolerance.

One month after the end of chemotherapy, the patient began her 3D conformational radiotherapy on the excisional pocket (Figures 4-7). The dose received was $50 \mathrm{~Gy}$ in 25 fractions. The dose constraints to the organs at risk were acceptable in particular for the left kidney, the liver, and for the abdominal cavity.

Six months after the end of radiotherapy; no incidents were reported. An evaluation of the laboratory workup demonstrated renal clearance at $59.5 \mathrm{ml} / \mathrm{min}$ and normal hepatic function.

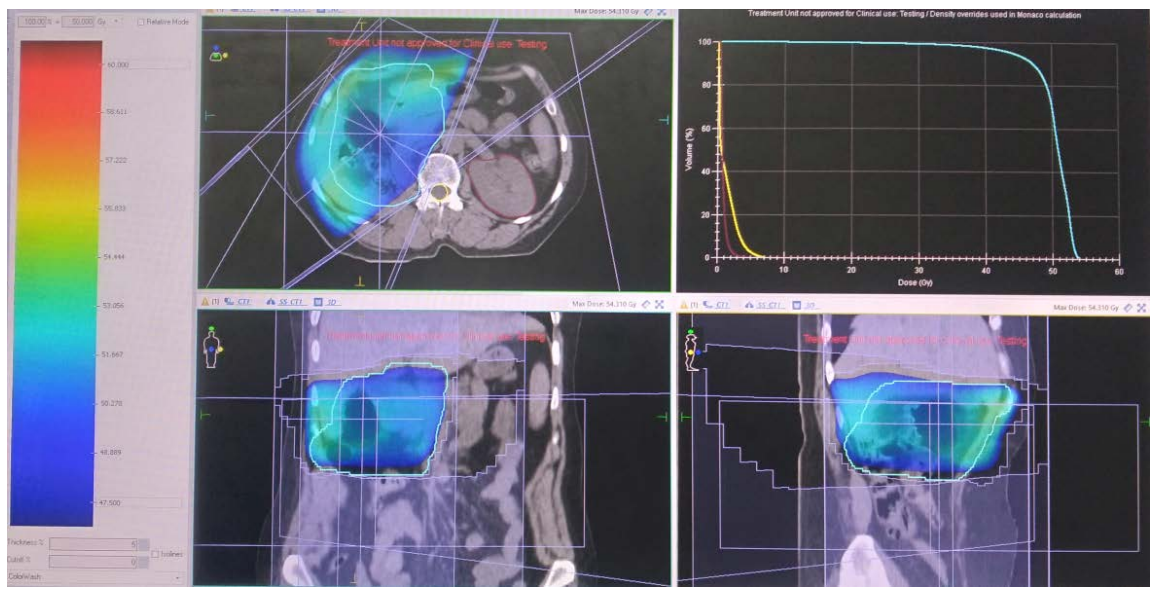

Figure 4. Dosimetry: distribution of milking fieldsis lying.

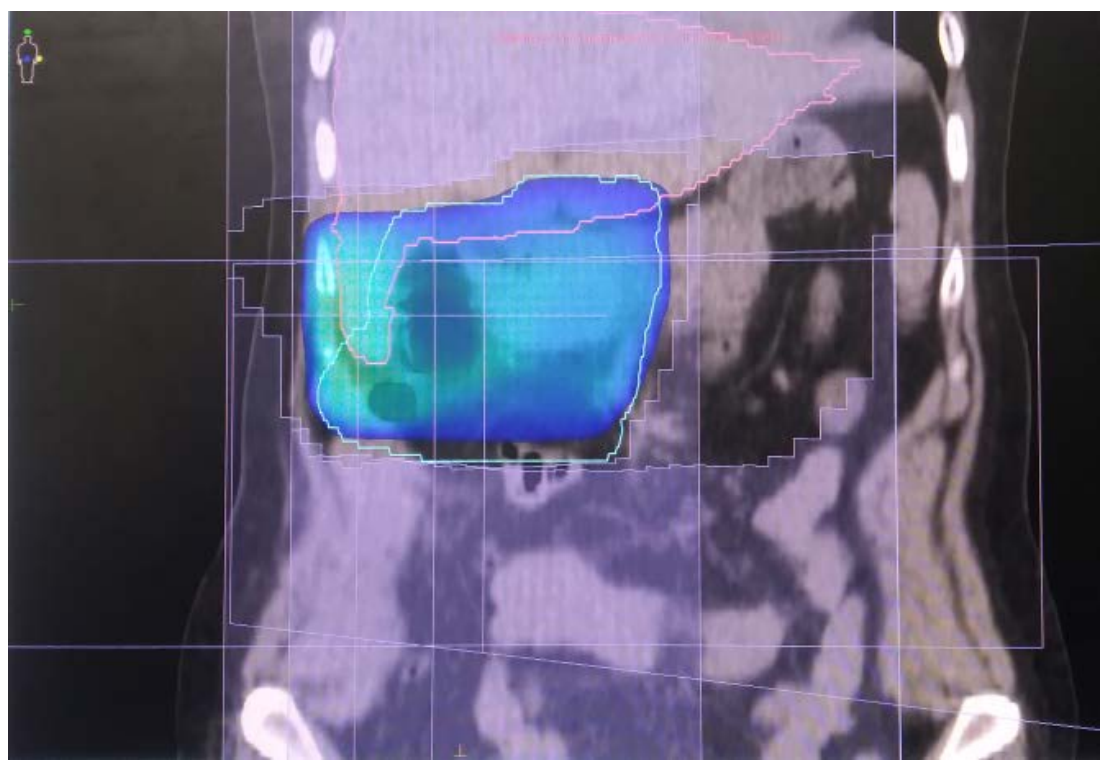

Figure 5. Frontal section: distribution of treatment fields. 


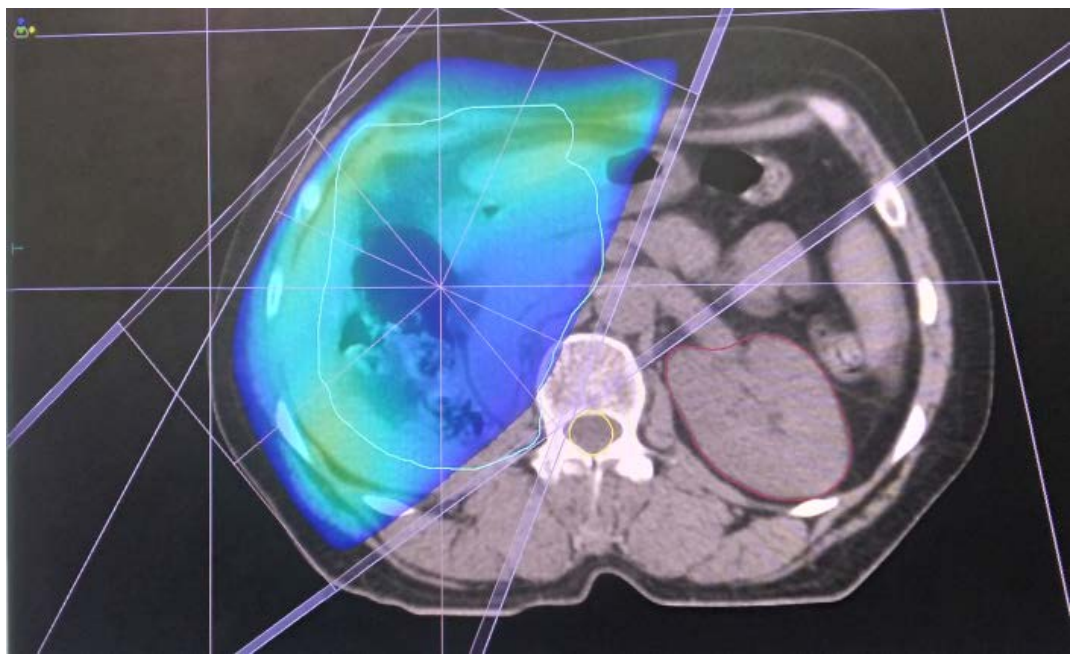

Figure 6. Axial section: distribution of treatment fields.

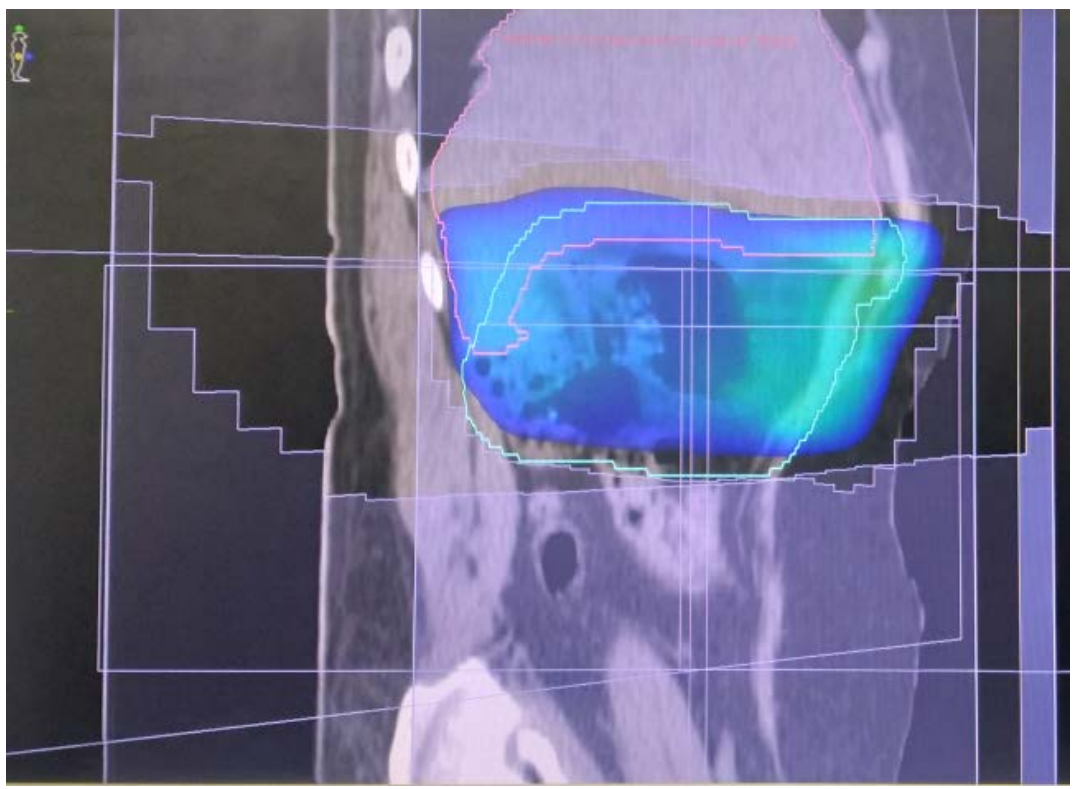

Figure 7. Sagittal section: distribution of treatment fields.

\section{Discussion}

SVS is an exceptional tumor in its primary renal location. 114 cases have been reported since the case of Faria et al in 1999 [2] until 2016 [1].

SVS is a tumor of mesenchymal spindle cells that exhibits variable epithelial differentiation and specific chromosomal translocation and sensitive, $t(X ; 18)$ (SYT SSX). It results from the fusion of the synovial sarcoma X (SSX) gene (variant 1 or 2 most often) on the X chromosome (in Xp11) and the SYT gene (also called SS18, for synovialsarcoma translocation chromosome 18) on chromosome 18 (in 18q11). It has recently been reported that the SSX4 gene is also involved in such a translocation [3] [4].

Kidney SVS presents a diagnostic dilemma, as it resembles renal cell carcinoma, and no clinical or imaging features can help make a preoperative diagnosis. 
Its diagnosis is based on the morphological (spindle cell) and immunological profile of the tumor. It can also be established by genetic analysis via FISH and RT-PCR, demonstrating the translocation of the SYT18-SSX gene.

It can appear under three different histological aspects: monophasic (exclusively formed by monomorphic areas of spindle-shaped cells), biphasic (coexistence of spindle-shaped and epithelial cells) or poorly differentiated. The monophasic form as in our observation seems to be more common and of better prognosis [5].

The lungs and liver are the most common sites of metastasis for renal SVS [6] [7].

Although synovialosarcoma of the kidney is considered an aggressive form, it has been shown to be sensitive to anthracycline-based chemotherapy [8]. Thereby; the therapeutic modalities comprising surgical resection such as enlarged nephroureterectomy followed by adjuvant chemotherapy based on Ifosfamide and Doxorubicin have given positive results. According to the literature, [3] [9] [10] [11], however, the interest of complementary radiotherapy is debated.

Further studies of a larger number of cases of primary renal SVS are needed to provide more knowledge regarding appropriate treatment and follow-up.

\section{Conclusions}

Primary kidney SVS is a rare disease, and can be confused with other types of renal cell carcinoma. For that; a molecular biology analysis by RT-PCR demonstrating the SYT-SSX translocation is required.

Renal SVS is very aggressive and the prognosis is poor, hence the interest in multimodal treatment based on surgical resection and adjuvant radiochemotherapy.

\section{Authors' Contributions}

MZ wrote the article; SX, RH, HJ, TC, ZB, NB, NT, SS, And AB made critical assessment of the article. All authors read and approved the final version of the manuscript.

\section{Consent for Publication}

Written informed consent was obtained from the patients for publication of this case report and any accompanying images.

\section{Conflicts of Interest}

The authors declare that they have no competing interests.

\section{Author Details}

Mohammed VI Center for Cancer Treatment, Ibn Rochd University Hospital, Casablanca, Morocco.

\section{References}

[1] El Chediak1, A. and Mukherji1, D. (2018) Sally Temraz1 Primary Synovial Sarcoma 
of the Kidney: A Case Report of Complete Pathological Response at a Lebanese Tertiary Care Center. BMC Urology, 18, Article No. 40.

https://doi.org/10.1186/s12894-018-0358-Z

[2] Faria, P., Argani, P. and Epstain, J. (1999) Primary Synovial Sarcoma of the Kiddney: A Molecular Subset of So-Called Embryonal Renal Sarcoma. Modern Patholo$g y, 12,94$.

[3] Kohle, O., et al. (2015) Soft Tissue Sarcomas of the Kidney. Rare Tumors, 7, 43-45. https://doi.org/10.4081/rt.2015.5635

[4] Chittoria, N. (2013) BIR Renal Cell Carcinoma. http://www.clevelandclinicmeded.com/medicalpubs/diseasemanagement/nephrolog y/renal-cell

[5] Long, J.A., Dinia, E.M., Saada-Sebag, G., Cyprien, J., Pasquier, D., Thuillier, C., et al. (2009) Primary Renal Synovial Sarcoma: A Cystic Tumor in Young Patients. Progrès en Urologie, 19, 474-478. https://doi.org/10.1016/j.purol.2009.01.018

[6] Lacovelli, R., et al. (2012) Clinical and Pathological Features of Primary Renal Synovial Sarcoma: Analysis of 64 Cases from 11 Years of Medical Literature. BJU International, 110, 1449-1454. https://doi.org/10.1111/j.1464-410X.2012.11105.x

[7] Ozkan, E.E., Mertsoylu, H. and Ozardali, H.I. (2011) A Case of Renal Synovial Sarcoma Treated with Adjuvant Ifosfamide and Doxorubicin. Internal Medicine, 50, 1575-1580. https://doi.org/10.2169/internalmedicine.50.5224

[8] Karavasilis, V., Seddon, B.M., Ashley, S., Al-Muderis, O., Fisher, C. and Judson, I. (2008) Significant Clinical Benefit of First-Line Palliative Chemotherapy in Advanced Soft-Tissue Sarcoma: Retrospective Analysis and Identification of Prognostic Factors in 488 Patients. Cancer, 112, 1585-1591. https://doi.org/10.1002/cncr.23332

[9] Park, S.J., et al. (2004) A Case of Renal Synovial Sarcoma: Complete Remission Was Induced by Chemotherapy with Doxorubicin and Ifosfamide. The Korean Journal of Internal Medicine, 19, 62-65. https://doi.org/10.3904/kjim.2004.19.1.62

[10] Markovic-Lipkovski, J., et al. (2013) Rapidly Progressive Course of Primary Renal Synovial Sarcoma-Case Report. Srpski Arhiv Za Celokupno Lekarstvo, 141, 814-818. https://doi.org/10.2298/SARH1312814M

[11] Mishra, S., et al. (2015) Primary Synovial Sarcoma of the Kidney. Saudi Journal of Kidney Diseases and Transplantation, 26, 996-999.

https://doi.org/10.4103/1319-2442.164590

\section{Abbreviations}

SVS: Synovialosarcoma 